\title{
Den homosociale voldtægtskultur
}

\section{Af SARA GJERMANDSEN}

\section{Abstract}

Ved at analysere Jane Campions tv-serie, Top of the Lake, ønsker jeg gennem etableringen af en ny strukturel model at bidrage til en ny læsning af utopisk og dystopisk feministisk fiktion, hvorved begrebet voldtægtskultur (rape culture) nuanceres.

Gennem en samlæsning af to anerkendte begreber indenfor kønsforskning, nemlig Gayle Rubins 'Traffic in Women' og Eve Sedgwick Kosofskys 'Homosocial Desire', etablerer jeg en model med hvilken en række feministiske utopiske og dystopiske værker, Top of the Lake inklusiv, kan læses som repræsentationer og forhandlinger af voldtægtskultur som 'Male Bonding by Traffic in Women'.

I anden del af artiklen flyttes fokus over på seriens kvindekoloni, i hvilken en gruppe kvinder har etableret et helle, hvori de forsøger at undslippe og bearbejde den maskuline dominans og den mere konkret seksuelt baserede vold, de har oplevet. Her inddrages Ann Cvetkovichs affektteoretiske begreber 'insidious trauma' og 'Public Trauma Cultures'. Seriens kvindesamfund vil her blive diskuteret som en kultur, hvori det private ikke blot er politisk, det er selve fundamentet for den nationale identitetsdannelse. Det snigende (voldtægts)traume gøres til et nationalt traume og dermed også synligt.

\section{KEYWORDS}

affektteori, voldtegtskultur, homosocialitet, traumekulturer, feministisk kulturkritik/ affect theory, rape culture, homosociality, trauma cultures, feminist cultural criticism.

Sara Gjermandsen er videnskabelig assistent i Koordinationen for Kønsforskning, ekstern lektor ved Gender Studies på DIS og styrelsesmedlem i Dansk Kvindesamfund. Hun har en kandidat i Engelsk fra Københavns Universitet. 


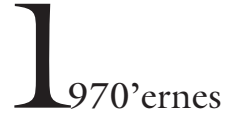

radikalfeministiske begreb, voldtægtskultur, er i løbet af de sidste par år re-aktualiseret indenfor den feministiske samfundskritik. Samtidig har begrebet, for første gang siden sin opståen, for alvor indtaget mainstreamkulturen og den offentlige debat og ligeledes affødt de nye begreber, slut-shaming og victim-blaming. Hvor begrebet voldtægtskultur oprindeligt blev skabt, for at italesætte det amerikanske samfunds indgroede accept af seksuel vold imod kvinder, understreger slut-shaming og victim-blaming, hvordan ofre for seksuelle overgreb tillægges skyld, samt massemediernes andel i mistænkeliggørelsen af ofrene i voldtægtssager, ved gentagende at italesætte ofrenes påklædning, alkoholpromille og seksuelle historie som årsag til overgrebet.

Jane Campions miniserie Top of the Lake fra 2013 er i en anmeldelse i det feministiske magasin Ms. Magazine blevet rost for at afbillede voldtægtskultur i sin reneste form. Serien skriver sig ind i en feministisk litterær tradition, hvor kvindesamfund undersøges som henholdsvis feministiske utopier og dystopier. Indenfor denne lidt oversete genre portrætteres modstand mod vold og seksuelle overgreb imod kvinder som selve fundamentet for disse mandeløse samfund. Ligesom tidligere eksempler på genren' belyser Top of the Lake de magtforhold, der opretholdes og reproduceres ved de homosociale samfundsstrukturer, der understøtter mænds kontinuerlige promovering af mænds interesser. Samtidig har genren, mere eller mindre ukritisk, forestillet sig kvinders homosocialitet som frugtbar, altruistisk og progressiv. Her bidrager Campions serie med et særligt kritisk blik på de homosociale aspekter af det feministiske utopia, og lader den fejle på den mest pinagtige facon. I serien møder vi politibetjenten, Robin Griffin, som spilles af Elisabeth Moss. Hun er vendt hjem til sin barndomsflække for at være sammen med sin døende mor. Men straks efter sin ankomst involveres hun i efterforskningen af den gravide 12 årige Tuis forsvinden. Griffin konfronteres igennem sagen med den gruppevoldtægt, hun som 16 årig selv blev udsat for, af en flok drenge fra sin skole, og som resulterede $\mathrm{i}$ en graviditet og, at hun forlod byen. Igennem de seks afsnit bliver det klart, at vold og overgreb er en del af dette minisamfunds sociale norm og Robin møder voldsom misogyni på tværs af sociale skel og ikke mindst fra det lokale politi, som hun nu skal samarbejde med. Udenfor byen opstår en kvindelejr, hvor vold og overgreb forsøges bearbejdet og på sigt undgået. Men kvinderne, der ikke er fra lokalområdet og som har forestillet sig at kunne skabe et frirum her opdager snart, at vold og overgreb også lurer her.

Jeg ønsker $\mathrm{i}$ artiklen at bidrage med en strukturel model, kaldet 'Male bonding by traffic in women'. Med modellen læses voldtægtskultur inden for denne genre som funderet i homosociale magtstrukturer. I modellen sammenlæses Eve Kososfsky Sedgwicks begreb homosocialitet, hendes forståelse af termen 'male bonding', samt hendes bearbejdning af Gayle Rubins begreb 'Traffic in Women'. En sådan sammenstilling er frugtbar, fordi de sammen forbinder det etablerede antropologiske begreb 'kinship systems' og en kritik af LeviStrauss' ukritiske tilgang til kvinder som handelsvare imellem mænd, med homosocialt begær, for derved at belyse nye perspektiver på voldtægtskultur som mænds udveksling af kvinder som seksuelle objekter.

Med modellen, samt affektteoretiske perspektiver fra Ann Cvetkovichs An Archive of Feelings vil jeg undersøge, hvordan disse bidrager til forståelsen af Campions portrættering af mænd og kvinders homosociale fællesskaber som forsøg på henholdsvis at fastholde voldtrgtskultur og at nedbryde den. 


\section{HETEROSEKSUALITET SOM HOMOSOCIAL MAGTSTRATEGI}

I between Men, et hovedværk indenfor queerteoretisk litteraturkritik, problematiserer Sedgwick, hvad hun oplever som en binær sondring imellem mænds homosociale og homoseksuelle relationer. Homosocialitet og homoseksualitet opfattes, ifølge Sedgwick, blandt kvinder som mindre dikotomisk end blandt mænd og ikke nødvendigvis som værende i diakritisk opposition. Hun tilskriver dette:

"an intelligible continuum of aims, emotions and valuations" (Sedgwick 1985: 2)

Heteroseksualitet er en underforstået faktor i male bonding, da mandlig homosocialitet er defineret i opposition til mandlig homoseksualitet. De fleste tekster der berører patriarkalske strukturer, antyder, ifølge hende, det modsatte. Obligatorisk heteroseksualitet er integreret i mandlige kinship systems og homofobi er accepteret som en nødvendig konsekvens af den patriarkalske institution, det heteroseksuelle ægteskab. Det har tilsyneladende været umuligt at forestille sig en form for patriarkat, der ikke er homofobisk. Men blot fordi de fleste patriarkater strukturelt omfatter homofobi, betyder det ikke, at patriarkatet strukturelt nødvendigvis kræver homofobi.

Vi kan, ifølge Sedgwick, tage det som et aksiom, at de historisk differentierede former for mandlig og kvindelig homosocialitet altid vil være del af opretholdelsen af mænd og kvinders ulige adgang til magt, fordi mænds homosociale bånd og fællesskaber aktivt inkluderer eksklusion af kvinder, samt promoveringen af mænds interesser på bekostning af kvinders.

I Between Men formuleres det desuden, hvordan voldtægt er en manifestation af sammenhængen mellem seksualitet og magthæudelse. Det mandlige homosociale begær udforskes samme sted, i analysen af William Wycherley skuespil The Country Wife fra 1675. Stykkets skildring af en gruppe aristokratiske mænds udveksling af deres hustruer, eksemplificerer den heteroseksuelle kærlighed, som en strategi for mandligt homosocialt begær:

"the men's heterosexual relationships have as their raison d'etre an ultimate bonding between men." (Sedgwick 1985, 50)

Ved at udvide denne læsning af heteroseksuelle relationer som homosocial magtstrategi til også at omfatte handlingen voldtægt, kan man læse seksuelle overgreb som mænds voldelige forsøg på at sikre deres egen deltagelse i det homosociale frellesskab.

Ligesom tidligere eksempler fra genren, skildrer Top of the Lake et samfund, hvor mænd cirkulerer kvinder som seksuelle kommoditeter, for dermed at styrke de implicerede mænds homosociale bånd.

I ethvert mandsdomineret samfund er der, ifølge Sedgwick, en særlig forbindelse mellem det mandlige homosociale begær og strukturerne for vedligeholdelse og overførsel af patriarkalsk magt. Argumentet understreger den måde, hvorpå voldtægt $\mathrm{i}$ Top of the Lake er portrætteret, nemlig som fundamental i opretholdelsen af det eksisterende magthierarki. Mens radikalfeminismen forstår voldtægt som et symptom på mandlig dominans og kvindelig objektivering i et patriarkalsk samfund, identificerer queer perspektiver på voldtxgt dem som ikke blot et redskab til at sikre maskulin dominans, men også et instrument, der anvendes for at opretholde den heteroseksuelle orden. Begge tilgange til spørgsmålet om voldtægt og begrebet voldtægtskultur tilbyder værdifulde perspektiver på samfundsstrukturer, der legitimerer voldtægt.

\section{ETABLERING AF HOMOSOCIALE \\ FÆLLESSKABER VIA FÆLLES SEKSUELLE TERRITORIER}

På et formelt besøg hos den lokale narkobaron, Matt Mitcham (Mitcham), som også 
er far til den forsvundne gravide 12-årige Tui, spørger overbetjent Al Parker (Parker), hvilken af Mitchams voksne sønner, der er far til det barn, som sidder hos en for ham tydeligvis ukendt ung kvinde i Mitchams køkken. Både Mitcham og kvinden viger fra at besvare spørgsmålet. Scenen lader seeren tilbage med den mistanke, at Mitcham måske selv er far til barnet. I en senere episode afbryder han sin søn og samme kvinde $i$ at ligge og have sex $i$ hans seng. Mitcham synes ikke at tage særlig notits af synet, og hans stiltiende accept af situationen kan, hvis vi medlæser Sedgwicks teorier om mænds kanalisering af deres homosociale begær til hinanden igennem en kvinde, pege på, hvorledes far og søn fastcementerer deres relation ved at dele seksuelt territorie. Vi hører aldrig kvindens navn, hun er både navnløs og uden replikker. Hun fremstår som en rekvisit i Micham og hans sønners hjem - et udskifteligt objekt imellem Mitcham og hans søn.

Sedgwick bruger René Girards læsning af den erotiske trekant ${ }^{2}$ i sin læsning af et udsnit af William Shakespeares sonetter, og argumenterer for, at figuren i flere eksempler kan bruges til at understrege, hvordan den heteroseksuelle kærlighed her kan læses som sekundær til de rivaliserende mænds homosociale relation. Ligeledes påpeger hun, hvordan kvinden i trekanten bruges som mellemled i kommunikationen imellem de to mænd, samt hvordan handlingen, at dele seksuelle territorier for trekantens yngre mand, kan sikre homosocialt fællesskab med en $x$ ldre mand og eventuelt medføre en mere privilegeret position i magthierarkiet:

It is a way of participating in a supraindividual male power over women, and of being close to more fully entitled males.

(Sedgwick, 1985: 36-37)

I flere eksempler har den feministiske litteraturs kønsopdelte utopier og dystopier portrætteret voldtægt som mænds forsøg på at indgå i homosociale fællesskaber med mere priviligerede mænd. Dette er også tilfældet i Top of the Lake.

Ligesom Mitcham er overbetjent Parker portretteret som en hyper-maskulin patriark. Han er en lokal autoritetsfigur, der foruden rollen som håndhæver af loven, også høster anerkendelse for sit engagement i en socialøkonomisk virksomhed, hvor socialt udsatte børn fra lokalområdet, herunder Tui, uddannes som baristaer med det formål at give dem både selvtillid, arbejdsmoral og en lysere fremtid. Det viser sig dog, at de jævnlige filmaftener, som børnene inviteres til hos Parker, ender i hans kælder, hvor børnene, bedøvede af rohypnol, filmes, imens Parker og særligt inviterede mænd med magt og penge, voldtager dem. I løbet af serien undres den nyligt hjemvendte kriminalbetjent, Robyn Griffin da også over, hvordan en statsansat politibetjent kan leve som en jetsetter, med luksusvilla og egen båd. Parker har gjort sin adgang til de udsatte børn til en rentabel virksomhed, hvorved han både har profiteret økonomisk, men også opnået homosociale bånd til mere privilegerede mænd i lokalsamfundet.

Mitcham ønsker ikke politiet eller de sociale myndigheder involveret i sagen om hans gravide 12 årige datter. Parker advarer ham om, at en kvindelig betjent, nemlig den udefrakommende Griffin, har fået sagen. Dette synes implicit at varsle, at en kvinde potentielt kan true magtbalancen i dette hyper-maskuline mikrokosmos og måden, hvorpå det lokale politi ellers ville vende det blinde øje til seksuelle overgreb på kvinder og børn. Da Tui kort inden sin forsvinden, efter at være blevet afhørt på politistationen, returneres til sin far, og det bekreftes, at hun er gravid i femte måned, er Mitchams eneste kommentar til sin datter:

"You didn't talk, and that was good" (Campion 2013). 
Både Mitcham og Parker personificerer den fundamentale objektivering og kommodificering af kvinder. Deres karakterer forholder sig udelukkende til kvinder som potentielle kommoditeter, med hvilke de kan promovere egne interesser. Ved at inddrage min model vises det, hvordan deres foragt for kvinder muliggør deres engagement i den kontinuerlige cirkulation af male bonding igennem handel med kvinder. Sedgwick finder Gayle Rubins analyse og kritik af Claude Lévi-Strauss yderst relevant, især hendes diskussion af 'traffic in Women' som en nøgle til kvinders undertrykkelse og tilføjer:

"Women are used as exchangeable property for the primary purpose of cementing the bonds of men with men" (Sedgwick

1985:26).

Ved at portrættere et feministisk dystopia, hvori handlen med kvinder og børn accepteres og promoveres i både toppen og bunden af samfundet, eksemplificerer Top of the Lake dette argument.

Mitcham og Parker, skønt ved første øjekast modsætninger, placeret på hver deres side af loven, viser sig nemlig at være en del af samme struktur. Begge mænd har højstatus i lokalsamfundet, samt magt og privilegier til at gøre nøjagtig, hvad der passer dem. Begge cementerer deres fællesskab med andre mænd igennem forhandlingen med kvinder eller børn som seksuelle objekter. Og begge profiterer på rollen som hanrej, hvorved de styrker deres position $\mathrm{i}$ det homosociale frllesskab.

Mitcham og Parker repræsenterer to forskellige klasser, men identificerer sig dog begge med meget traditionelle maskuline idealer. Begge synes at føle sig berettigede til at besidde kvinder. I Mitchams tilfælde henviser han til alle kvinder $\mathrm{i}$ sit liv som "my bitches" (Campion 2013), både de kvinder, der arbejder i narkotikalaboratoriet i hans kælder, den unge kvinde med hvem han har et barn, og også sin egen datter
Tui. Alle falder ind under hans ejerskab, og alle forventes at bidrage til hans position som en alfahan. Robin Griffin er en trussel imod begges mænds position og privilegier. Både i kraft af sin status af udefrakommende, samt generelle autoritet som håndhæver af loven, men også fordi hun udfordrer deres opfattelse af, hvor meget indflydelse en kvinde bør have i den offentlige sfære. Derfor forsøger begge mænd også aktivt, ved brug af de klassiske kinship systemer, at repositionere hende som passivt objekt i den private sfære. Parker frier til hende og taler om muligheden for at få et barn sammen, mens Mitcham forsøger at overbevise hende om, at han er hendes biologiske far. Medtænker vi Rubin, peger begge forsøg på den magt det institutionaliserede slægtskab har i kønnenes magthierarki.

\section{KANALISERINGEN AF MÆNDS HOMOSOCIALE BEGÆR IGENNEM KVINDERS KROPPE}

I en række flashbacks viser serien, hvordan Griffin som 16 årig til en skolefest blev angrebet på skolens parkeringsplads, kørt til et afsides sted og voldtaget af en gruppe drenge fra sin skole. Da hun efter sin hjemkomst som voksen møder en af sine voldtægtsforbrydere, genkender han hende ikke. Sedgwick argumenterer for, at samfundets struktur underordner mænd og kvinders relationer, mænds homosociale bånd:

In the total scheme of things, men's bond with women are meant to be in a subordinate, complementary, and instrumental relation to bonds with other men. (Sedgwick 1985: 51)

Hvis vi inddrager denne ide kan voldtxgtsforbryderens manglende evne til at huske Robin læses som et tegn på hendes funktion som en tilfældig genstand, igennem hvilken hendes voldtægtsforbrydere rodfæstede deres homosociale begær imod hinanden. 
Hvis vi skal følge Lévi-Strauss' ide om mænds udveksling af kvinder som et grundlæggende princip i vores samfundsstruktur, så kan vi se underordningen af kvinder, som et produkt af forholdet med hvilken det biologiske køn og kulturelle køn produceres og organiseres i det dikotomiske forhold imellem forhandler og handlet. Dette kan tyde på, at mænds homosociale fællesskaber igennem handel med kvinder, bidrager til deres objektificering og dermed voldtagelighed.

Top of the Lake viser et miljø, hvor mænd bistår hinanden $\mathrm{i}$ et kontinuerligt, konsekvensløst misbrug af byens kvinder og børn. Dette til skade for mere end ofrene for de enkelte forbrydelser. Vi ser, hvordan venner, kærester og familier til voldtægtsofrene er fortvivlede, og hvordan deres liv også ændres af sådanne begivenheder, sådan som Wilson hævder:

rape culture seeps into the lives and loves of those raped - for years, for decades, rippling out into generations, spreading through families, trickling down into every corner of existence. (Wilson 2013)

Serien adresserer, hvordan voldtægtskultur og idealiseret hyper-maskulinitet ikke kun påvirker de direkte ofre, men alle der lever $\mathrm{i}$ et samfund med en sådan accept af overgreb og udnyttelse. Robins ven og ungdomskæreste, Johnno, er efterladt følelsesmæssigt forkrøblet efter at have overværet hendes voldtægt. Da han som voksen angriber en af hendes voldtxgtsforbrydere, undgår han det traditionelle heteronormative narrativ, ved at afstå fra at kalde hende sin kæreste, og dermed indskrive dem i et $\mathfrak{x g -}$ teskab/ejerskabsnarrativ. I stedet understreger Johnno deres ligeværdige relation ved at sige:

"You raped my friend" (Campion 2013).

I en scene på den lokale bodega virker de lokale mænd tydeligt provokerede af Robin
Griffins åbenlyse foragt for deres ligegyldighed $\mathrm{i}$ forhold til, at en 12 årig pige er gravid og forsvundet. En spørger hende:

“Are you a feminist?"

Mens en anden tilføjer:

“Are you a lesbian? You'd be better off being a lesbian ... nobody likes a feminist except a lesbian” (Campion 2013).

Det gøres altså Griffin klart, at i dette minisamfund bør kvinder ikke ytre sig imod den herskende fordeling af magt og privilegier. Der går sport $\mathrm{i}$ at provokere den nyankomne storby-feminist og mændene fortsætter med at tale om glæderne ved submissive asiatiske kvinder. En af mændene går så vidt, som at inddrage Tui i den snak og kalde hende deres allesammens 'poon-tang'. Robin Griffin kvitterer med en dartpil i hans skulder.

Mændene får her gjort opmærksom på, at hun enten kan forblive kritisk overfor det lille samfunds voldtægtskultur og hermed acceptere positionen som uønsket i en heteroseksuel kontekst, eller underkaste sig samfundsnormen og dermed blive anerkendt som attraktiv:

With its exploration of "unfuckcable-ness," the show circulates around the narrow gender confines that frame females as one of two things: fuckable (and thus "good") or unfuckable (and thus bad/feminist/lesbian)... However, as the narrative reveals, being fuckable, which is one entry into "good femininity," also carries the threat of rape and sexual assault. (Wilson 2013)

Ser man Top of the Lake i forlængelse af den litterære tradition den indskriver sig i, er det interessant, hvordan den ligesom tidligere eksempler på feministiske utopier og dystopier fungerer som et forstørrelsesglas på verdenen udenfor papiret eller i dette tilfælde skærmen. I dette dystopiske mikro- 
kosmos sker der intet, der ikke også sker i verdenen på den anden side af skærmen. Samtidig bidrager serien med et nyt blik på begrebet voldtrgtskultur, ved at modstå genrens tidligere eksemplers hang til at inddrage den radikalfeministiske forestilling om mænds aggressive seksualitet som biologisk determineret.

\section{FEMINISEREDE MÆND}

Jane Campion lader forsøget på at skabe et mandefrit feministisk utopia mislykkedes. På en jordlod med det mytologisk klingende navn 'Paradise', slår en gruppe kvinder, med guruen GJ som overhoved, lejr. Alle kommer de med et ønske om at bearbejde deres erfaringer med vold, undertrykkelse og seksuelle overgreb. En af lejrens beboere, Anita, forklarer en del af sin historie med voldelige relationer. Dråben der fik bægeret til at flyde over, og Anita til at søge tilflugt i lejren, blev hendes kæledyr, aben Brads transformation fra kærlig følgesvend til besidderisk, voldelig og fæcesslyngende. Efter at have fået Brad aflivet, er Anita kommet til lejren, Camp Eden, for at gøre op med sin fortid og undgå flere voldelige mænd i sit liv. Men Camp Eden ændrer ikke det faktum, at Anita er blevet socialiseret til at acceptere og endda opsøge misbrug og overgreb. Umiddelbart efter sin ankomst til lejren indleder hun et forhold til Mitcham, som efter deres første date kører hende over med sin firehjulstrækker, alt imens han brøler

"See what you fucking made me do" (Campion 2013).

Mens Campion med mere end et strejf af ironi, punkterer den radikale idé om kønsapartheid som mulig modstand mod vold og overgreb, tilbyder hun i stedet et opnåeligt alternativ, hvilket jeg kommer nærmere ind på senere i artiklen.

Sedgwick argumenterer for, hvordan mænd for at kunne tjene kvinders interes- ser, må fjerne sig fra det homosociale fællesskabs kredsløb. Ved at inkludere dette argument i læsningen af Top of the Lake, understreges sammenhængen mellem to af seriens mandlige figureres nære venskaber og solidaritet med kvinder og deres isolation fra resten af byens mænd.

Seriens karakterer, Johnno og Jamie, tjener som trofaste venner for Robin og Tui. Begge mænd er udelukket fra alle aspekter af male bonding i det samtømrede hypermaskuline samfund, de lever i. Deres udelukkelse fra dette privilegiefremmende fællesskab synes at være lige så meget en aktiv tilbagetrækning som en udskilning. Johnno og Jamie imødekommer ikke de samfundsmæssige forventninger om mandlig kønsidentitet som brutal, voldelig og eksploitiv, hvilket resulterer i deres feminisering. Således trækker både Johnno og Jamie sig ud af rollen som rival, og henvises dermed til rollen som passivt objekt, hvilket nok tydeligst portræteres i scenen, hvor den mindreårige Jamie i politiets forhørslokale, forholder sig roligt og tavst, imens han udsættes for både fysisk og verbal vold, straffen for at nægte at afsløre Tuis gemmested. Som mandlige karakterer kan de læses som tegn på håb, eksempler på mænd, der udfører modstand mod voldtxgtskultur ved at afstå fra deltagelsen i dominans og seksuel udnyttelse af kvinder som led $\mathrm{i}$ et magtproducerende mandefællesskab.

Sedgwick henviser til, hvordan karakteren Horner I The Country Wife :

represents himself, and is perceived by some women, not only as excepting himself from the male homosocial circuit, but as making a sacrifice of his (homosocially defined) masculinity, in favour of the pleasure of women. (Sedgwick 1985: 56)

Figuren Horner påpeger nogle interessante magtstrukturer i sin omgangskreds, nemlig at en jæunbyrdig relation til kvinderne, nødvendigvis betyder en udgrænsning af mandefællesskabet. For at beholde sin sta- 
tus og sine privilegier, er han derfor nødsaget til at skjule sine venskaber med kvinder. Denne pointe fremhæver, hvordan kvindehad er obligatorisk inden for male bonding, samt hvorledes en mand som åbenlyst anerkender kvinder som mere end cirkulerbare seksuelle objekter, ikke samtidig kan deltage i det homosociale fællesskab med andre mænd eller opnå de privilegier, der følger med den inklusion. Johnno og Jamie eksemplificerer argumentet, at det at være uden for det homosociale fællesskab, der forudsætter at mænd kontinuerligt forfordeler og fremmer andre mænds interesser, gør dem i stand til at engagere sig i ligeværdige relationer til kvinder.

Liggende nøgen i sengen ved siden af Robin deler Johnno, hvordan hans liv har været, siden hun forsvandt ud af hans liv efter den skæbnesvangre nat, hvor han magtesløst så til, imens deres klassekammerater voldtog hende på skift. Hans afmagt, skyldfølelse og vrede har resulteret $i$, at han har isoleret sig:

"Not loving anyone. Not knowing a woman deeply, that made me sad." (Campion 2013)

Samtidig har Johnnos afvisning af at bidrage til den voldtægtskultur, som hersker hvor han bor betydet, at han er blevet fremmedgjort fra sin far og sine brødre, såvel som resten af det mandsdominerede samfund. Han ses ikke længere som et aktiv i cirkulationen af magt og maskulin dominans. I en sexscene imellem Robin og Johnno overfaldes Johnno af sine egne brødre der har ligget på lur og filmet dem og penetreres på tung symbolsk vis, da en af dem dolker ham $\mathrm{i}$ låret med en kniv. Konsekvensen af Jamies udelukkelse fra det homosociale frellesskab er ultimativ, da han i et forsøg på at beskytte sin nu højgravide veninde Tui ved at aflede opmærksomheden fra hendes fars brutale eftersøgningshold, iklæder sig hendes jakke og i Tuis sted jages ud over en klippeskrænt og dør. Hans voldsomme død ved hånden af $\mathrm{Mi}$ - tchams hyper-maskuline håndlangere bliver katalysator for et oprør mod Mitcham og det lille samfunds udveksling og kommercialisering af kvinder og børn.

Ved at gøre brug af modellen 'Male bonding by Traffic in Women', kan feministisk utopisk og dystopisk fiktion, såsom Top of the Lake, ses som bidragende med alternative positioner i forhandlingerne af de underliggende homosociale samfundsmæssige strukturer i voldtægtskultur, såvel som transformativt potentiale, ved at tilbyde tværkønnede alliancer som aktiv modstand. Sedgwick skriver i Between Men om mænds homosociale begær og dets anatomi:

The homosociality of this world seems embodied fully in heterosexuality; and its shape is not that of brotherhood, but of extreme, compulsory, and intensely volatile mastery and subordination. (Sedgwick 1985: 66)

Top of the Lake portretterer netop et samfund, hvor overgreb og undertrykkelse som magtredskab er indlejret i selve fundamentet, og hvor både ofrene og modstanden eksisterer på tværs af kønsidentitet, hvilket nedbryder det system, i hvilket homosocialt begær maskeres, som heteroseksuelt begær. Serien belyser, hvorledes voldtægt ikke sker i forlængelse af et utæmmeligt heteroseksuelt begær, men som led i en magtproducerende strukturelt voldelig cirkulation af homosocialt begxr.

\section{FRA SNIGENDE TRAUME \\ TIL NATIONALT TRAUME}

I modsætning til de mere etablerede definitioner af begrebet traume, definerer Cvetkovich i indledningen til An Archive of Feelings traumer som:

"experiences of socially situated political violence" (Cvetkovich 2003: 3).

Seksuelle traumer forbliver i vid udstrækning usynlige på grund af den kønnede op- 
deling mellem den private og offentlige sfærer. Judith Herman, professor i klinisk psykiatri på Harvard Medical School, hævder, at de reelle forhold for kvinder er skjulte i kraft af sin plads i den private sfere, samt at traumediskursers historie er dybt indlejret i debatter om køn og seksualitet samt forholdet mellem offentlige og private sfærer (Lewis 1992). Cvetkovich understreger feministisk teoris indflydelse på og betydning for udviklingen i traume teorier og kalder Herman for en af de vigtigste feministiske traumeeksperter. Cvetkovich tilgang til traumer er influeret af Hermans bidrag til et feministisk perspektiv på trauma og hendes arbejde for at få integreret seksuelle traumer og krigstraumer.

Definitionen af traumer som oplevelser af socialt situeret politisk vold, knytter ifølge Cvetkovich forbindelse mellem politik og følelser. I modsætning til mere oplagte geopolitiske katastrofer, som krig og folkedrab, udforsker Cvetkovich den slags følelsesmæssige oplevelser, der går tabt i traditionelle traumediskurser. Dette har nødvendiggjort en overvejelse af en åbenbar kønsopdeling indenfor traumediskurs, der resulterer i en usynliggørelse af seksuelle traumer. Dette kan tilskrives dens placering i hjemmet og den private sfære, samt manglen på døde eller lemlæstede kroppe i sit umiddelbare kølvand.

Statussen som nationalt traume muliggør ifølge Sedgwick en kollektiv bevidsthed og anerkendelse af det bagvedliggende og undertrykkende system, som ligger til grund for alle disse erfaringer. Disse skaber grobund for kollektiv modstand mod selvsamme system.

Cvetkovich fremhæver konsekvenserne af at leve med systemisk vold som sexisme, som en hverdagserfaring, og hvordan det snigende traume bidrager til mere åbenlyse traumer, som voldtrgt. Cvetkovich finder forfatter og ph.d. i psykologi, Laura Browns begreb 'snigende traume' (insidious trauma) afgørende for at kunne beskrive de daglige erfaringer med sexisme, der øger effekten af mere direkte traumatiske oplevelser såsom voldtægt, som det smeder forbindelser mellem traumer og flere systemiske former for undertrykkelse.

Ifølge Cvetkovich skal et traume opnå status som et nationalt traume, for at den kollektive helingsproccess kan begynde. Hun diskuterer, hvordan aktivisme, performance og litteratur giver anledning til at forme offentlige kulturer, der bearbejder traumer og samtidig omdanner de sociale betingelser, der producerer dem. Ved at fokusere på kulturelle reaktioner på traumer forsøger hun at modstå de medicinske diskurser og især diagnosen post-traumatisk stres. Som Susan Billingham, forfatter og lektor i canadiske studier ved University of Nottingham, skriver i sin essaysamling fra 2010:

Cvetkovich defines trauma in relation to culture and not just clinically, emphasising the need for collective rather than individual solutions. ( Billigham 2010)

I min læsning af Cvetkovich, vil jeg fokusere på de specifikke begreber; snigende traumer og nationale traumer, samt traumekulturer, forstået som offentlige kulturer dannet omkring seksuelle traumer. Snigende traumer, fordi det behandler temaet kollektive oplevelser af voldtægt og seksuelt misbrug, som er nyttig i diskussionen af begrebet voldtægtskultur og dens repræsentation i feministisk fiktion. Nationalt traume, fordi det bidrager med et konkret koncept for at begribe de måder, hvorpå synligheden af traumer er væsentlige for disses placering i en kollektiv, national identitet. Traumekulturer, defineret som offentlige kulturer grundlagt omkring seksuel traumer, giver mulighed for en læsning af kollektiv behandling af seksuelle traumer gennem kunst og performance som en måde at fremhæve de snigende seksuelle traumer, og gøre dem til en del af den offentlige og nationale identitet. I Top of the Lake er udnyttelse af byens kvinder og børn omsiggri- 
bende og alligevel usynlig. Byen er tavs om overgrebene, og udnyttelsen synes for de lokale at være en nødvendighed for opretholdelsen af samfundet. Den stiltiende accept kommer i sidste ende kun de allermest privilegerede til gode, de som direkte profiterer på cirkulationen af tilgængelige kroppe. Resten af det lille samfund lider, også de, der aktivt opretholder voldtægtskulturen. I Camp Eden er tavsheden i bedste basisgruppestil brudt, og lejren fungerer som et spejl for samfundet på den anden side af lågen.

\section{CAMP EDEN SOM FEMINISTISK TRAUMEKULTUR}

I An Archive of Feelings definerer Cvetkovich feministiske traumekulturer som:

"public cultures that form in and around trauma."(Cvetkovich 2003: 9)

Kan Camp Eden læses som en repræsentation af en sådan feministisk traumekultur?

Cvetkovich påpeger, hvorledes feministisk kunst kan være et redskab til en kollektiv bearbejdning af seksuelle traumer og understreger nødvendigheden af at tilvejebringe et alternativt rum til diskussionen af seksuelle traumer:

The combined power of song, visuals, and live performance lend itself to the formation of a public culture around trauma that doesn't involve medical diagnosis or victims. (Cvetkovich 2003: 1)

Ved kollektivt at behandle seksuelle traumer gennem kunst og performance hævder Cvetkovich, at traumer overføres fra det private til det offentlige rum, hvilket muliggør at det opnår status som nationalt traume:

It is important to incorporate affective life into our conceptions of citizenship and to recognize that these affective forms of citizens- hip may fall outside the institutional practices that we customarily associate with the concept of a citizen. (Cvetkovich 2003: 11)

Ved at påpege traumekategorien som utilstrækkelig og ekskluderende, åbnes der for traumatisering, som en ikke nødvendigvis isolerende situation eller udelukkende individuel erfaring:

"Exploring how trauma can be a foundation for creating counter-public spheres rather than evacuating them."(Cvetkovich 2003: 15)

De sexisme-inducerede snigende traumer gør ifølge Cvetkowich kvinder passive og mindre tilbøjelige til at gøre indsigelse mod mere synlige traumatiske oplevelser såsom seksuelt misbrug. En kultur, hvor objektivering af kvinder resulterer i maskuline privilegier, så som retten til fri afbenyttelse af kvindekroppe, skaber en forventning om seksuelle overgreb blandt kvinder. Den indkoder dem til en passiv position som voldtagelige, seksuelle objekter. En affektiv tilgang kan vise sig nyttig, når teoretiske begreber ikke yder tilstrækkelig kompleksitet i tilgangen til seksuelle traumer, da det ofte ikke manifesterer sig som et individuelt kohærent narrativ. Ofte er det mere kompliceret, da det kædes sammen med oplevelser og historier, der ikke nødvendigvis er ens egne kropslige erfaringer. Cvetkowich berører vigtigheden af at anerkende virkningerne af de kollektive erfaringer af overgreb. Den enkelte hændelse af voldtægt traumatiserer ikke kun det enkelte offer, men bidrager også til det kollektive seksuelle traumer af at leve i en voldtægtskultur, og berører dermed:

"those whose experiences circulate in the vicinity of trauma and are marked by it." (Cvetkovich 2003: 3)

Mens Top of the Lake på mange måder portrætterer en forfejlet feministisk utopi, til- 
byder den i stedet en affektiv tilgang til den kollektive bearbejdning af traumer gennem performance. Vi ser, hvordan Jamies mor med hjælp fra to af beboerne i Camp Eden trækker Jamies livløse krop op af det kolde vand og ind i lejren, hvor en kollektiv sorgproces manifesterer sig igennem både visuelle udtryk og lyd. Vi ser to heste med ordet "NO" skrevet på deres sider, og vi hører ekkoet af Tuis skrig og riffelskud rikochettere mellem bjergene. Lejrens kvinder udfører i fællesskab sangen Joga af den islandske musiker Björk, mens Jamies mor, hendes venner, Jamies venner og andre folk fra byen stimler sammen for at græde, kramme og lytte til musikken. Scenen eksemplificerer det helbredende aspekt af den kollektive traumebearbejdning. Musikken ekkoer i bjergene, mens en tekstbid fra sangens omkvæd gentages:

"State of emergency, how beautiful to be. State of emergency is where I want to be." (Björk 1997)

Top of the Lakes underliggende feministiske vision bidrager, i scener som denne, med kollektiv katarsis. Det synes at være den aristoteliske definition af katarsis, altså en følelsesmæssig purgation gennem kunst, der undersøges. Ved flere lejligheder er musik portrætteret som et redskab til både at udtrykke og udleve følelser. Men i tråd med Cvetkovichs kritik af terapiens tilgang til seksuelle traumer, afviser også GJ, Guruen i Camp Eden, kvindernes søgen efter den terapeutiske katarsis. Camp Eden viser både potentialet, men bestemt også begrænsningerne i forsøget på at undslippe seksuelle traumer ved at skabe en mande-fri zone. GJ afviser kvindernes søgen efter lykke og klarhed, og på et tidspunkt konstaterer hun, at:

"All the bitches here are searching for love. When they don't find that, for enlightenment. They don't find anything"(Campion 2013).
I det afsluttende afsnit henvender GJ sig til den samlede gruppe af kvinder i lejren og konstaterer at deres vision om at skabe et rum for emotionel udrensning er fejlet:

We are living out here at the end of the road, the end of the earth in a place called paradise. How is it going? Perfect? No. You are madder than ever (Campion 2013).

De enkelte kvinder formår ganske rigtigt ikke at arbejde igennem eller bevæge sig ud over deres egne historier og oplevelser af vold og seksuelt overgreb. Trods al deres meditation og udveksling af historier synes de ikke i stand til at ændre deres egne adfærdsmønstre. Heller ikke GJs gentagende anvisninger om ikke at meditere, men i stedet at give efter og acceptere, at der ikke er nogen vej $\mathrm{ud}$, ingen måde at undslippe smerten.

Beboerne i Camp Eden har ikke et fælles mål, og kvindernes individuelle søgen efter at undslippe traumevirkningerne af at leve i en voldtægtskultur viser sig utopisk, uopnåeligt.

Men mens Camp Edens beboeres søgen efter terapeutisk katarsis og åndelig klarhed svigter, snubler de som fællesskab over noget andet. De formår nemlig at skabe et rum for kollektiv behandling af snigende traumer, konsekvensen af at leve i et samfund, hvor kvinder og børn misbruges og kommercialiseres. Björks sangtekst understreger, at kvinderne endelig har gjort, hvad GJ undervejs forgæves vejledte dem til at gøre. De er langt om længe holdt op med at løbe og accepterer den undtagelsestilstand, der forener dem.

DEN FEMINISTISKE UTOPIS FALDGRUBER OG POTENTIALE

I Beauvoir's Utopia: The Politics of the Second Sex, argumenterer Toril Moi for feminismens behov for utopien: 
Feminism is a movement that requires a vision of something else: a utopian perspective which inspires and informs the struggle against present oppression. (Kitch 2000: 97)

Et tilbagevendende tema i både utopisk og dystopisk feminist fiktion er spørgsmålene om kvindeundertrykkelse og mandlig aggression. De litterære dystopier portrættere samfund med institutionaliseret seksuel vold imod kvinder, brugt for at sikre deres passivitet og domesticering, mens det feministiske utopiske samfund opstår i opposition til sådanne samfundsstrukturer og, som Sally L. Kitch påpeger i Higher Ground: From Utopianism to Realism in American Feminist Thought and Theory:

"guarantees perfect safety for its inhabitants, especially from rape or assault" (Kitch 2000: 68).

Camp Eden er billedet på et forfejlet feministisk utopia, men samtidig et portræt af en feministisk traumekultur, som opstår ud af den kollektive stræben efter at forstå og ændre de vilkår, som ligger til grund for traumet. Jane Campion, som både er instruktør og forfatter til serien, forklarede i et interview, at hun mener, at serien skildrer hvordan:

"The closer you get to the so-called ideal, the more painful it is because it doesn't work" (Wilson 2013).

Denne observation peger velsagtens på det problematiske ved blindt at stole på utopisk tænkning, men Camp Eden peger samtidig også på utopiens transformative potentiale, der ligger i rejsen mod denne. Kitch hævder, at utopisk tænkning er frugtbar for så vidt, at den åbner op for nye muligheder og foregribende opfindsomhed, men ufrugtbar i det, at den beskriver umuligheder som reelle muligheder. Ifølge Kitch, skaber utopisk feminisme retoriske udsagn som:
"Let's just lock up all the men and see the world improve."(Kitch 2000: 26)

Den kritik er tildels god nok, omend den drastiske udelukkelse af mænd i disse fiktive feministiske utopiaer i reglen er midlertidige. Målet er igen at inkludere mænd, når de, alt efter værkets biologiske eller socialkonstruktiviske tilgang, enten via dannelse eller selektion, frivilligt opgiver deres privilegier og indgår i det nye samfund på lige vilkår med kvinderne. I serien besøges kvindelejren flere gange af mænd og disse forvises kun, når de udviser truende og aggressiv adfærd. Målet er ikke at holde mænd ude, men at skabe et rum, hvor kvinderne føler sig trygge nok til frit at kunne bearbejde deres historie og de følelser denne har affødt. Hvad der ofte kendetegner en feministisk utopi, er ifølge den amerikanske forfatter Joanna Russ, dens evne til:

"allowing room for female rage and female self-defence"

og dens evne til at være:

"serious about the emotional and physical consequences of violence"( Kitch 2000: 26).

Dette korrelerer med den måde, som feministisk utopisk fiktion defineres af Frances Bartkowski, der mener feministiske utopier formår:

"demanding revolutionary transformation that reshapes desire, anger, and despair into the contours of hope."(Kitch 2000: 62)

Sammenstillingen af Cvetkovichs definition af feministiske traumekulturer og Bartkowskis definition af den feministiske utopi understreger, hvordan feministiske utopier som kulturelle tekster kan levere en fremragende ramme til at forestille sig alternative samfund. Cvetkovich hævder, at et sammenbrud af sondringer kan forene det affektive- og det offentlige liv. I tidligere ek- 
sempler på genren, i hvilken Top of the Lake indskriver sig, lader de feministiske utopiaer disse sondringer gennemtrænge hinanden ved at fusionere det offentlige og det private. Dette skaber samfund, i hvilke affekt og følelser ikke devalueres som logikkens anden, men snarere ses som kernen i udviklingen af et retfærdigt samfund og som central i konstruktionen af den nationale identitet.

Genren bidrager igennem sine repræsentationer af feministiske traumekulturer med transformativt potentiale, og eksemplificerer på den måde Cvetkovichs definition af offentlige traumakulturer, ved at den den representere:

"examples of how affective experiences can provide the basis for new cultures"(Cvetkovich 2003).

\section{Noter}

1. D’aulnoy, Marie Catherine: L'ile de la félicité, 1690, Sarah Robinson: Millennium Hall, 1762, Bradley, Mary E: Mizora - A Prophecy, 1880, Gilman, Charlotte Perkins: Herland, 1915, Tepper, Sheri S.: The Gate to Women's Country, 1988, Lessing, Doris: The Cleft, 2006, Hessérus, Madeleine: Staden Utan Kvinnor, 2012.

2. Girard sporede en kalkule af magt, struktureret af rivaliseringen mellem de to aktive medlemmer af en erotisk trekant. Indenfor den europæiske finkulturs mandligt-centrerede romantradition, var den trekant Girard oftest sporede den, hvor to mænd var rivaler om en kvinde, hvilket betyder, at det $\mathrm{i}$ vid udstrækning var bindingen mellem mænd han afdækkede.

\section{LITTERATUR}

· Björk (1997): Joga, Homogenic (album). Campion, Jane and Gerard Lee (20139, Top of the Lake, BBC Two, UKTV, Sundance Channel.

- Buchwald, Emilie, Fletcher, Pamela, Martha Roth (1993): Transforming a Rape Culture, Milkweed's Edition, USA.

- Billigham, Susan (2010): Il/legitimacy, from Feminism, Literature and Rape Narratives: Violence and Violation, (eds. Gunne, Sorcha, Zoe Brigley), Routledge, UK.

- Cvetkovich, Ann (2003): An Archive of Feelings Trauma, Sexuality, and Lesbian Public Culture, Duke University Press, USA.

- Herman, Judith Lewis (1992): The Aftermath of Violence - from Domestic Abuse to Political Terror, Cambridge: Harvard University Press, USA - Kitch, Sally L (2000): Higher Ground: From Utopianism to Realism in American Thought and Theory, The University of Chicago Press, Chicago - Moi, Toril (1993): Beauvoir's Utopia: The Politics of the Second Sex, Duke University Press, USA.

- Rubin, Gayle (1975): Traffic in Women - Notes on the political economy of sex, from Rayna Reiter's Toward an Anthropology of Women, New York, Monthly Review Press.

- Sedgwick, Eve Kosofsky (1985): Between Men English Literature and Male Homosocial Desire, Columbia University Press, New York.

- Wilson, Benji (2013), Jane Campion interview for Top of the Lake: The world is focused on sexiness, The Telegraph.

-Wilson, Natalie: Top of the Lake: A Non-Watered-Down Depiction of Rape Culture, Ms. Magazine, 2013 